\title{
Emotion matters for academic success
}

\author{
Implications of the Article by Jarrell, Harley, Lajoie, and Naismith (2017) \\ for creating nurturing and supportive learning environments to help \\ students manage their emotions
}

\author{
Xun $\mathrm{Ge}^{1}$ \\ Accepted: 26 November 2020 / Published online: 11 January 2021 \\ (c) Association for Educational Communications and Technology 2021
}

\begin{abstract}
This paper is in response to the published article entitled "Success, failure and emotions: examining the relationship between performance feedback and emotions in diagnostic reasoning" (Jarrell, Harley, Lajoie, \& Naismith, Education Technology \& Research Development, 65, 1263-1284: 2017) focusing on its implications to inform educational practice and research as learning and instruction are shifted to digital environments in times of emergencies and crisis. The study explored the relationships between learners' retrospective performance outcome emotions and their academic performance (i.e., efficiency and accuracy). The results revealed that positive emotions were associated with higher performance while negative emotions were associated with poorer performance, and the low intensity emotions were associated with performance between high and low levels. A summary of the study reported by the article is provided, including the purpose, methods, measures, data analysis and findings. Following the summary, the paper focuses on the discussion about the focused perspective, values and impact of the study on digital learning environments with implications for education during the COVID-19 pandemic and other emergency situations. Based on Jarrell and her colleagues' study, suggestions are made for designing and developing instructional strategies to support students with negative or low intensity emotions and for creating learning environments to cultivate positive emotions. This paper concludes with recommendations for future research.
\end{abstract}

Keywords Academic performance $\cdot$ Positive emotions $\cdot$ Negative emotions $\cdot$

Alternativeinstructional delivery $\cdot$ Remote learning $\cdot$ Real-time conference $\cdot$ Self-regulation

Xun Ge

xge@ou.edu

1 The University of Oklahoma, Norman, OK, USA 


\section{Summary}

The article entitled "Success, failure and emotions: examining the relationship between performance feedback and emotions in diagnostic reasoning" (Jarrell et al. 2017) reported a study that investigated the impact of various performance emotions resulting from the feedback of their academic outcomes on learners' future academic performance and outcomes. A quantitative study was conducted among 30 medical students to explore the relationship between the students' outcome emotion profiles and their performance on diagnostic reasoning tasks in a computer-based learning environment. Retrospective questionnaires were used to measure learners' academic achievement emotions, and academic performance was measured by assessing the participants' efficiency and the accuracy in solving problems of three cases. The participants' solutions were compared with the expert's solutions. Through cluster analysis, it was found that participants classified to the positive emotion cluster had the highest performance; those classified to the negative emotion cluster had the lowest performance; and those classified to the low intensity emotion cluster had performance outcomes that fell between the highest and the lowest performance.

\section{Focused perspective}

The results of the study by Jarrell et al. (2017) imply the importance of emotional aspect in learning, which has been recognized by some researchers but often overlooked in education (Cleveland-Innes and Campbell 2012; Lehman 2006). Online or remote learning presents more challenges to students not only cognitively and socially, but also emotionally (Cleveland-Innes and Campbell 2012), particularly during the COVID-19 pandemic. The cluster analysis of various types of emotional dimensions and their relationships with the performance outcomes provides information to help educators to focus more on learners with negative emotions or low intensity emotions, who need more scaffolding than students with positive emotions. Therefore, by identifying different kinds of performance feedback emotions, educators are justified to allocate their time, effort, and resources accordingly to those students who need more help.

\section{Impact and value}

As classes have been moved online due to the COVID-19 pandemic, both students and educators have experienced unprecedented disruptions to their regular school learning and classroom instruction. They are being forced to make necessary changes, adjustments, and transitions to an alternative delivery mode of instruction through asynchronous web-based instruction, real-time video conferencing or blended instruction. While the pandemic has left many teachers unprepared for teaching online or remotely, it has also left many students unprepared for receiving alternative methods of instruction due to the lack of selfdirected learning skills (e.g., planning, monitoring, and regulation). Due to insufficient preparation and training for teaching online or remotely, many educators are in short of experience in organizing, delivering, and evaluating learning in an alternative format. Such a situation may further affect students who have found themselves in a completely new and unfamiliar learning environment. It might cause their anxiety and add to their stress. 
Therefore, such a circumstance demands a higher level of self-planning, self-monitoring, and self-regulation skills. Given such a chaotic disruption, the emotional responses, such as stress, overwhelming, frustration, and dissatisfaction, can be felt by many students, whose academic performance may be affected in varied degrees. Students' academic outcomes will stimulate different emotional responses, particularly those who fail to perform to their own or teachers' expectations. Poor grades may lead to negative emotions, which may further impact their academic performance and future learning if such kinds of emotions are not under control, and if no emotional support is provided to learners.

Therefore, Jarrell et al.'s (2017) study has several important implications for educational practice in delivering online instruction, either synchronous or asynchronous. It is suggested that scaffolds must be provided to students before, during, and after an instructional unit to help them develop learning strategies and maximize their chance for success. First, instructional strategies must be developed to cultivate learners' positive and pleasant emotions. To this end, instructors must be trained to design and develop an effective learning environment that is well organized, supported, nurturing, and conducive to learners' success. Secondly, throughout the learning process, educators must help students to develop various cognitive and metacognitive strategies, such as organization, study, note-taking, and time management skills, which will help leaners to better manage their learning process, materials, resources, time, and develop a study plan to actualize their learning goals (Pintrich 2000; Zimmerman 1995). O'Regan's (2003) study indicated various issues that could have an impact on learners' emotions, which included organizational, cognitive, social, time management and technology issues. Hence, scaffolding learners to manage various aspects of their learning will help them to improve their academic performance and boost their self-efficacy, which in turn leads to positive emotions, successful performance, and gratifying learning outcomes (Bandura 1997).

After students are informed of their performance outcomes, such as an examination grade, it is important to provide emotional support to students who have failed the examination and help them manage, self-regulate, and monitor their negative emotions (Pintrich 2000; Zimmerman 1995). Those students who have reacted negatively must be led to understand that failure does not indicate a value judgement on their learning ability. Their attention should be directed to understanding why they have failed, what specific difficulties and challenges they have encountered, and what strategies they can use to help them overcome their difficulties so that they can be scaffolded to develop a plan for future improvement and success. In addition, cultivating a nurturing online learning environment that addresses emotional presence, an element found by Cleveland-Innes and Campbell (2012) in their study, will help students to minimize the impact of negative emotions caused by their disatisfying performance.

\section{Constraints and suggestions for future work}

Jarrell and his her colleagues' (2017) research extends the emotion research to academic performance and outcomes, especially the impact of performance feedback emotions on learners' academic performance in online learning environments. Most importantly, their study identified the relationships between various emotion classifications and different levels of academic performance, which is an important contribution to applied educational research. That said, Jarrell et al.'s (2017) study did not explain why negative emotions lead to weak academic performance. Future research needs to further explore 
the relationship between self-efficacy, emotions, emotion monitoring and regulation, and academic performance (Bandura 1997; Pintrich 2000; Putwain et al. 2013; Zimmerman 1995). Additionally, specific strategies and tools are needed to help learners evaluate and manage their emotions when they experience unpleasant or negative emotions so that they can move forward positively. Since this study only focused on performance feedback emotions, it is suggested that future research be expanded to include other sources of emotions that might also have an impact on students' academic performance and their overall learning experience, particularly in online or remote learning environments. Lastly, further research can also be conducted to explore the relationships between emotional presence and other presences (i.e., social presence, cognitive presence, and teaching presence) (Garrison 2007) and understand the role of community support in enhancing positive emotions and overcoming negative emotions in an online learning environment (Cleveland-Innes and Campbell 2012).

\section{Compliance with ethical standards}

Conflict of interest The author has no relevant financial or non-financial interests to disclose.

Research involving human participants and/or animals This research does not involve any human participants or animals.

\section{References}

Bandura, A. (1997). Self-efficacy: The exercise of control. New York: Freeman.

Cleveland-Innes, M., \& Campbell, P. (2012). Emotional presence, learning, and the online learning environment. The International Review of Research in Open and Distance Learning, 13(4), 269-292.

Garrison, D. R. (2007). Online community of inquiry review: Social, cognitive, and teaching presence issues. Journal of Asynchronous Learning Network, 11(1), 61-67.

Jarrell, A., Harley, J. M., Lajoie, S., \& Naismith, L. (2017). Success, failure and emotions: Examining the relationship between performance feedback and emotions in diagnostic reasoning. Education Technology \& Research Development, 65, 1263-1284. https://doi.org/10.1007/s11423-017-9521-6.

Lehman, R. (2006). The role of emotion in creating instructor and learner presence in the distance education experience. Journal of Cognitive Affective Learning, 2(2), 12-26.

O'Regan, K. (2003). Emotion and e-learning. Journal of Asynchronous Learning Networks, 7(3), 78-92.

Pintrich, P. R. (2000). The role of goal orientation in self-regulated learning. In M. Boekaerts, P. R. Pintrich, \& M. Zeidner (Eds.), Handbook of self-regulation (pp. 451-502). San Diego: Academic Press.

Putwain, D., Sander, P., \& Larkin, D. (2013). Academic self-efficacy in study-related skills and behaviours: Relations with learning-related emotions and academic success. British Journal of Educational Psychology, 83(4), 633-650.

Zimmerman, B. J. (1995). Self-regulation involves more than metacognition: A social cognitive perspective. Educational Psychologist, 30(4), 217-221. https://doi.org/10.1207/s15326985ep3004_8.

Publisher's Note Springer Nature remains neutral with regard to jurisdictional claims in published maps and institutional affiliations.

Xun Ge Ph.D., is Professor of Learning Sciences in the Department of Educational Department, the University of Oklahoma. Her research involves ill-structured problem-solving, scaffolding, and designing digital learning environments (e.g., game-based, simulation-based, virtual reality, makerspace) to support learner skill development in problem representation, argumentation, mental models, and self-regulation. Her scholarly work intersects cognition, motivation, design, and assessment in various educational contexts. 